\title{
Novel bis-piperidinium and bis-pyrrolidinium compounds as versatile phase-transfer catalysts
}

\author{
Muhammad Jawwad Saif, Jamil Anwar, Munawar Ali Munawar, Muhammad Kashif, \\ and Muhammad Imran Asghar \\ Institute of Chemistry, University of the Punjab, Lahore 54590 - Pakistan \\ E-mail: jawwadsaif@gmail.com
}

Dedicated to Prof. Dr Jamil Anwar, Institute of Chemistry, University of the Punjab, Lahore - Pakistan

\begin{abstract}
Syntheses and applications of new bis-piperidinium and bis-pyrrolidinium compounds as effective two-center phase-transfer catalysts are presented. Applications of these catalysts have been explored in etherification and $\mathrm{N}$-alkylation reactions, and comparisons between these catalysts and traditional phase-transfer catalysts such as cetyltrimethylammonium bromide $(\mathrm{CTAB})$ and 1-ethyl-3-methylimidazolium chloride $\left(\mathrm{emim}^{+} \mathrm{Cl}^{-}\right)$are presented.
\end{abstract}

Keywords: Bis-piperidinium, bis-pyrrolidinium, bis-quaternary ammonium, phase-transfer catalysis

\section{Introduction}

Phase-transfer catalysis (PTC) has been proved as a practical methodology in organic synthesis due to its simplicity, mild reaction conditions, better yields, and safer environmental protocols. ${ }^{1}$ Phase-transfer catalysts have been successfully incorporated in $\mathrm{C}-\mathrm{O},{ }^{2} \mathrm{C}-\mathrm{S},{ }^{3} \mathrm{C}-\mathrm{N},{ }^{4}$ and $\mathrm{C}-\mathrm{C}$ bond formation, ${ }^{5}$ carbonylation, ${ }^{6}$ oxidation, ${ }^{7}$ reduction ${ }^{8}$ and stereoselectively controlled reactions. ${ }^{9}$ Bis-quaternary salts attracted chemists because of the unique properties of the low critical micelle concentration, having greater efficiency towards lowering the surface tension, and better solubility property as compared with conventional surfactants. ${ }^{10}$ These properties can be attributed to the great difference in molecular structures between conventional surfactants and bis-quaternary ammonium compounds. These advantages make bis-quaternary ammonium compounds qualify as phase-transfer catalysts in alkylations and other reactions. Multi-cationic phase-transfer catalysts have shown promising results in these areas, suggesting that more extensive study is required to investigate their potential. ${ }^{11-21}$ 
There has been a need for quantitative comparison between the phase-transfer catalytic activities of bis-quaternary ammonium salts and those quaternary ammonium compounds which bear a single quaternary nitrogen moiety. This fact instigated us to prepare new series of bispiperidinium and bis-pyrrolidinium dihalide compounds, (Figure 1) and to study their phasetransfer catalytic properties in some reported experimental procedures versus the conventional phase-transfer catalysts cetyltrimethylammonium bromide (CTAB) and 1-ethyl-3-methylimidazolium chloride $\left(\mathrm{emim}^{+} \mathrm{Cl}^{-}\right)$.

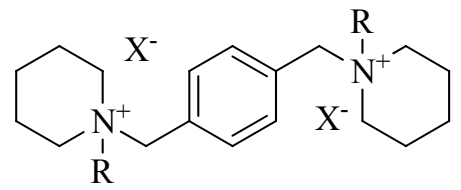

1a-11

1a: $\mathrm{R}=\mathrm{CH} 3 ; \mathrm{X}=\mathrm{I}$

1b: $\mathrm{R}=\mathrm{C} 2 \mathrm{H} 5 ; \mathrm{X}=\mathrm{Br}$

1c: $\mathrm{R}=$ allyl; $\mathrm{X}=\mathrm{Br}$

1d: $\mathrm{R}=\mathrm{C} 4 \mathrm{H} 9 ; \mathrm{X}=\mathrm{Br}$

1e: $\mathrm{R}=\mathrm{C} 6 \mathrm{H} 13 ; \mathrm{X}=\mathrm{Br}$

1f: $\mathrm{R}=\mathrm{C} 8 \mathrm{H} 17 ; \mathrm{X}=\mathrm{Br}$

1g: $\mathrm{R}=\mathrm{C} 12 \mathrm{H} 25 ; \mathrm{X}=\mathrm{Br}$

1h: $\mathrm{R}=\mathrm{C} 16 \mathrm{H} 33 ; \mathrm{X}=\mathrm{Br}$

1i: $\mathrm{R}=\mathrm{C} 18 \mathrm{H} 37 ; \mathrm{X}=\mathrm{Br}$

1j: $\mathrm{R}=$ benzyl; $\mathrm{X}=\mathrm{Br}$

1k: $\mathrm{R}=4$-bromobenzyl; $\mathrm{X}=\mathrm{Br}$

1l: $\mathrm{R}=3$-bromobenzyl; $\mathrm{X}=\mathrm{Br}$

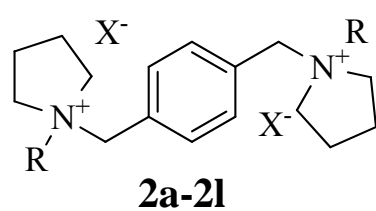

2a: $\mathrm{R}=\mathrm{CH} 3 ; \mathrm{X}=\mathrm{I}$

2b: $\mathrm{R}=\mathrm{C} 2 \mathrm{H} 5 ; \mathrm{X}=\mathrm{Br}$

2c: $\mathrm{R}=$ allyl; $\mathrm{X}=\mathrm{Br}$

2d: $\mathrm{R}=\mathrm{C} 4 \mathrm{H} 9 ; \mathrm{X}=\mathrm{Br}$

2e: $\mathrm{R}=\mathrm{C} 6 \mathrm{H} 13 ; \mathrm{X}=\mathrm{Br}$

2f: $\mathrm{R}=\mathrm{C} 8 \mathrm{H} 17 ; \mathrm{X}=\mathrm{Br}$

2g: $\mathrm{R}=\mathrm{C} 12 \mathrm{H} 25 ; \mathrm{X}=\mathrm{Br}$

2h: $\mathrm{R}=\mathrm{C} 16 \mathrm{H} 33 ; \mathrm{X}=\mathrm{Br}$

2i: $\mathrm{R}=\mathrm{C} 18 \mathrm{H} 37 ; \mathrm{X}=\mathrm{Br}$

2j: $\mathrm{R}=$ benzyl; $\mathrm{X}=\mathrm{Br}$

2k: $\mathrm{R}=4$-bromobenzyl; $\mathrm{X}=\mathrm{Br}$

2l: $\mathrm{R}=3$-bromobenzyl; $\mathrm{X}=\mathrm{Br}$

Figure 1. bis-Piperidinium and bis-pyrrolidinium compounds.

\section{Results and Discussion}

The novel bis-piperidinium and bis-pyrrolidinium compounds were prepared and evaluated for their phase-transfer catalytic activity in etherification and $\mathrm{N}$-alkylation reactions. The synthesis of bis-piperidinium compounds 1a-1l was carried out by amination of p-xylylene dibromide with two equivalents of piperidine followed by quaternization with alkyl bromides or iodides to produce the bis-quaternary compounds in good yields. (Scheme 1). The bis-pyrrolidinium compounds 2a-2l were prepared in a similar way by amination of $p$-xylylene dibromide with two equivalents of pyrrolidine followed by quaternization with alkyl bromides or iodides. (Scheme 2). 


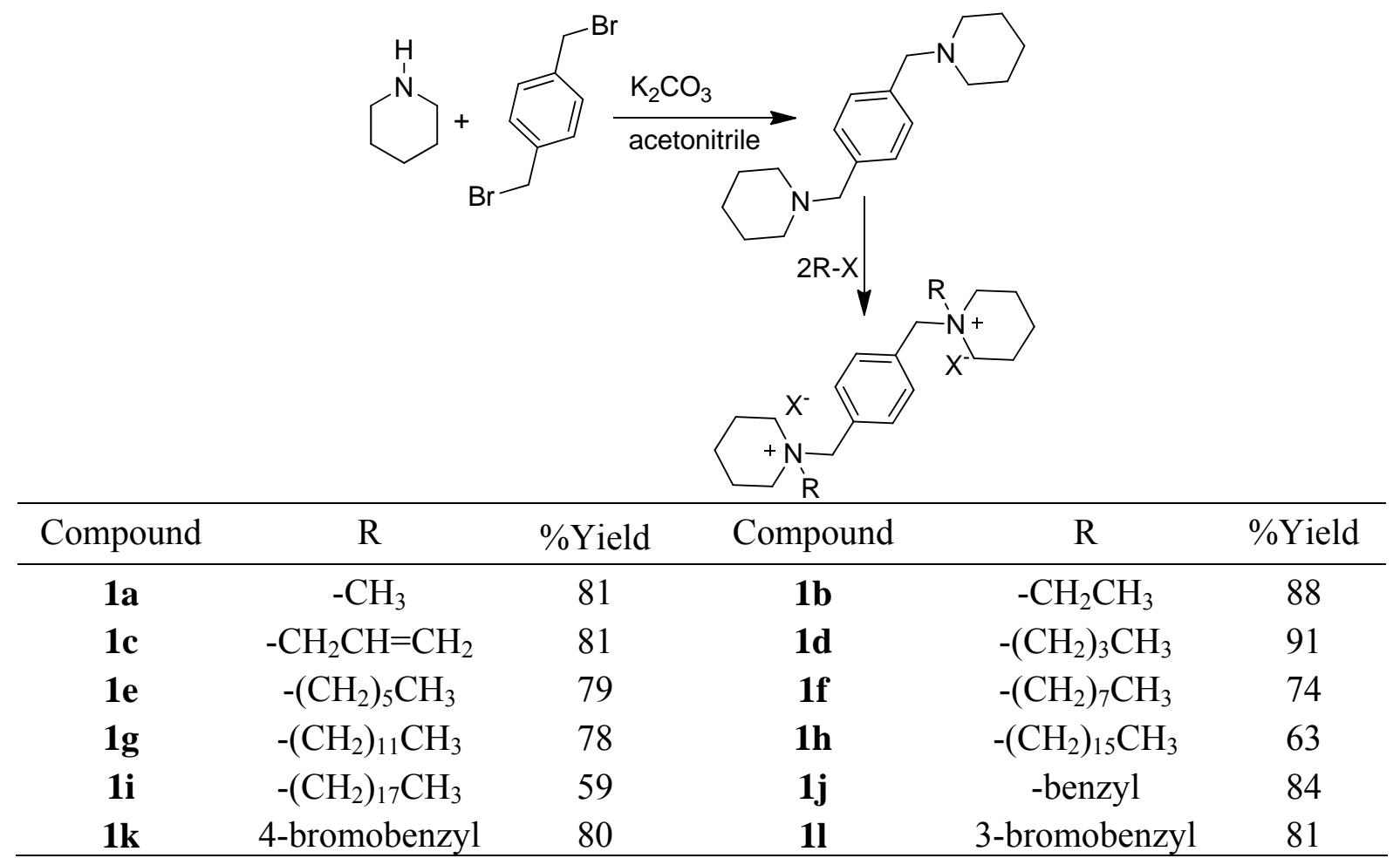

Scheme 1. Synthesis of bis-piperidinium compounds.

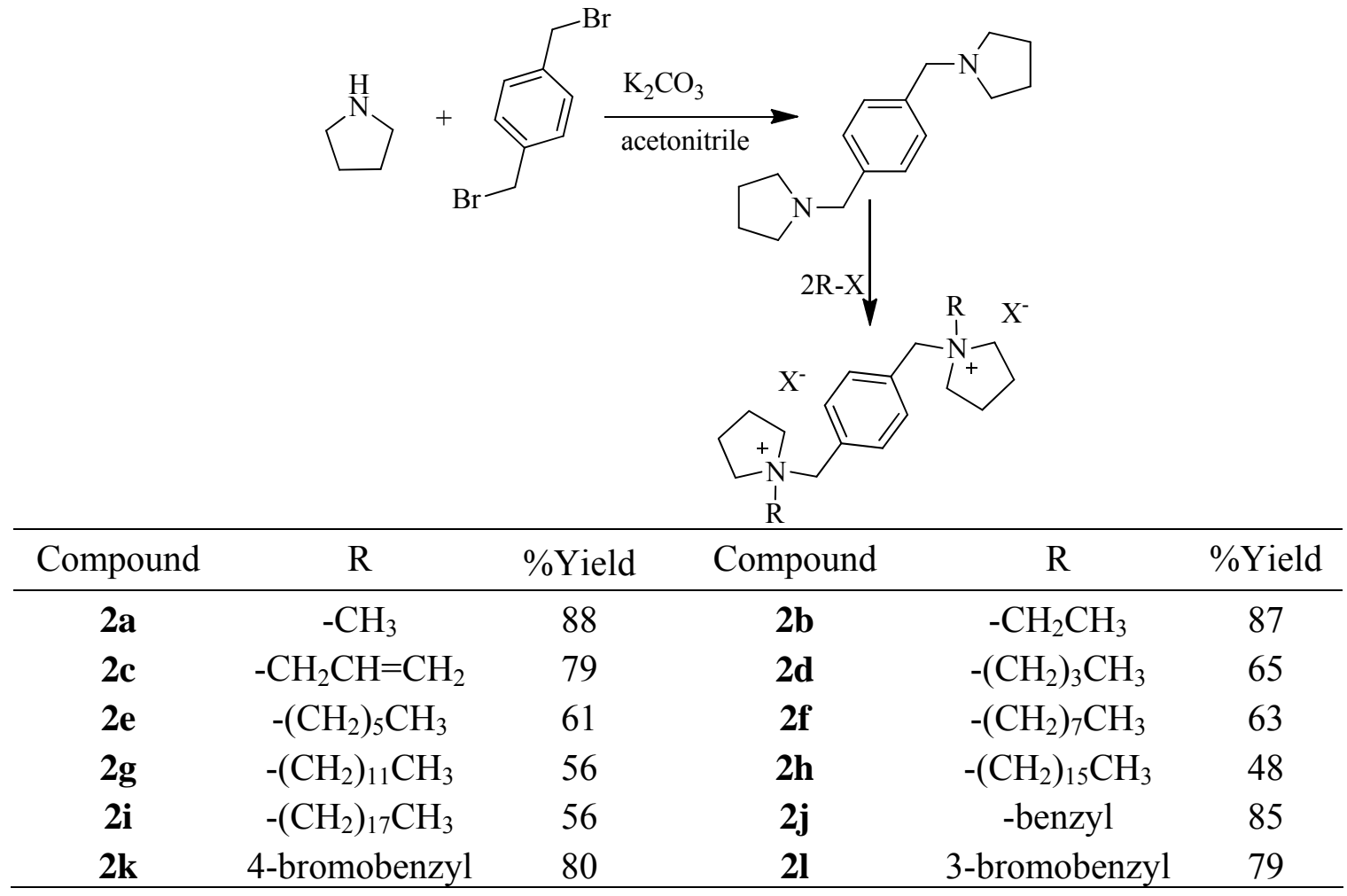

Scheme 2. Synthesis of bis-pyrrolidinium compounds. 


\section{Evaluation as PTC in etherification reaction}

The etherification reaction outlined in Scheme 3 was used as a model reaction to evaluate the phase-transfer catalytic behavior of bis-piperidinium 1a-1l and bis-pyrrolidinium compounds 2a2l. Experimental detail is provided in experimental section. Williamson etherification was chosen as a model reaction. Conversion rates for such etherification reactions are greatly increased when phase-transfer catalysts are used because of the improved transfer of watersoluble base into the organic phase. The reaction conditions were similar to the etherification reaction reported by Freedman and Dubois. ${ }^{22}$ This reaction was chosen because of the relatively high yields and less side reaction products. The etherification reaction was carried out with alkyl halides under PTC/aq.NaOH conditions where bis-piperidinium and bis-pyrrolidinium compounds 1a-11, 2a-2l were employed as phase-transfer catalysts (Scheme 3). The products were confirmed by spectroscopic methods. In separate experiments, etherification was repeated using the classical cetyltrimethylammonium bromide (CTAB) and 1-ethyl-3-methylimidazolium chloride $\left(\mathrm{emim}^{+} \mathrm{Cl}^{-}\right)$phase-transfer catalysts under the same experimental conditions in order to test phase-transfer activity of bis-quaternary compounds 1a-1l, 2a-2l against the classical monoquaternary ammonium compounds. The yields of the products were determined by HPLC analysis of the reaction mixture at the end of specified time. A better performance of bispiperidinium compounds against the classical phase-transfer catalysts is revealed from the results summarized in Table 1.

$$
\mathrm{n}-\mathrm{C}_{8} \mathrm{H}_{17} \mathrm{OH}+\mathrm{R}-\mathrm{X} \stackrel{50 \% \mathrm{NaOH} / \mathrm{PTC}}{\longrightarrow} \mathrm{C}_{8} \mathrm{H}_{17} \mathrm{OR}
$$

\begin{tabular}{|c|c|c|}
\hline Alkyl Halide & $=\mathrm{PhCH}_{2} \mathrm{~B}$ & 3a: $\mathrm{C}_{8} \mathrm{H}_{17} \mathrm{OCH}_{2} \mathrm{Ph}$ \\
\hline & $=\mathrm{PhCH}_{2} \mathrm{Cl}$ & 3b: $\mathrm{C}_{8} \mathrm{H}_{17} \mathrm{OCH}_{2} \mathrm{Ph}$ \\
\hline & $=n-\mathrm{C}_{4} \mathrm{H}_{9} \mathrm{Br}$ & 3c: $\mathrm{C}_{8} \mathrm{H}_{17} \mathrm{OC}_{4} \mathrm{H}_{9}$ \\
\hline
\end{tabular}

Scheme 3. Phase-transfer catalyzed etherification of 1-octanol.

Using the extraction mechanism, bis-piperidinium compounds were able to efficiently transfer base $\left(\mathrm{OH}^{-}\right)$into the organic phase where it extracted a proton from the alcohol. The resulted alkoxide then quickly reacted to produce the ether product. Bis-piperidinium compounds resulted in high conversions to the resulting ether after 60 minutes of agitation. The best conversions were achieved for compounds $1 \mathbf{1 d}, \mathbf{1 e}, \mathbf{2 d}$ and $\mathbf{2 e}$ which range up to $98 \%$ conversion to compound 3a. Cetyltrimethylammonium bromide provided a conversion up to $76 \%$ after the specified time whereas 1-ethyl-3-methylimidazolium chloride $\left(\mathrm{emim}^{+} \mathrm{Cl}^{-}\right)$did not produce high yields. 
Table 1. Phase-transfer catalyzed etherification of 1-octanol using bis-piperidinium and bispyrrolidinium compounds 1a-1l and 2a-2l as phase-transfer catalysts ${ }^{\mathrm{a}}$

\begin{tabular}{cccccccccc}
\hline Entry & PTC & \multicolumn{3}{c}{$\%$ Yield } & Entry & PTC & \multicolumn{3}{c}{$\%$ Yield $^{\text {a }}$} \\
& & 3a & 3b & 3c & & & 3a & 3b & 3c \\
\hline 1 & $\mathbf{1 a}$ & 82 & 55 & 52 & 16 & $\mathbf{2 a}$ & 69 & 41 & 39 \\
2 & $\mathbf{1 b}$ & 87 & 51 & 54 & 17 & $\mathbf{2 b}$ & 71 & 46 & 44 \\
3 & $\mathbf{1 c}$ & 95 & 76 & 62 & 18 & $\mathbf{2 c}$ & 78 & 52 & 60 \\
4 & $\mathbf{1 d}$ & 98 & 79 & 64 & 19 & $\mathbf{2 d}$ & 97 & 72 & 62 \\
5 & $\mathbf{1 e}$ & 97 & 71 & 65 & 20 & $\mathbf{2 e}$ & 98 & 74 & 68 \\
6 & $\mathbf{1 f}$ & 90 & 76 & 54 & 21 & $\mathbf{2 f}$ & 93 & 73 & 58 \\
7 & $\mathbf{1 g}$ & 92 & 73 & 57 & 22 & $\mathbf{2 g}$ & 94 & 67 & 51 \\
8 & $\mathbf{1 h}$ & 81 & 68 & 60 & 23 & $\mathbf{2 h}$ & 79 & 62 & 56 \\
9 & $\mathbf{1 i}$ & 67 & 51 & 51 & 24 & $\mathbf{2 i}$ & 61 & 49 & 47 \\
10 & $\mathbf{1 j}$ & 77 & 66 & 54 & 25 & $\mathbf{2 j}$ & 81 & 63 & 50 \\
11 & $\mathbf{1 k}$ & 81 & 62 & 52 & 26 & $\mathbf{2 k}$ & 77 & 60 & 57 \\
12 & $\mathbf{1}$ & 73 & 67 & 47 & 27 & $\mathbf{2 l}$ & 76 & 58 & 52 \\
13 & $\mathrm{CTAB}^{\mathrm{c}}$ & 76 & 65 & 61 & 28 & $\mathrm{CTAB}^{\mathrm{c}}$ & 76 & 65 & 61 \\
14 & emim $^{+} \mathrm{Cl}^{-\mathrm{c}}$ & 49 & 41 & 18 & 29 & emim $^{+} \mathrm{Cl}^{-}$ & 49 & 41 & 18 \\
15 & $\mathrm{None}^{\mathrm{c}}$ & 14 & 7 & 9 & 30 & $\mathrm{None}^{\mathrm{c}}$ & 14 & 7 & 9 \\
\hline
\end{tabular}

${ }^{a}$ All reactions, except entries 13-15 and 28-30 are conducted with 1-octanol (10 mmol), alkyl halide $(20 \mathrm{mmol})$, PTC $(0.8 \mathrm{mmol})$ and $5 \mathrm{ml}$ of $50 \%$ aq. $\mathrm{NaOH}$ at $90^{\circ} \mathrm{C}$ for $1 \mathrm{~h}$.

${ }^{b}$ Yields are determined by HPLC analysis of the reaction mixture after the reaction time indicated.

${ }^{\mathrm{c}} \mathrm{As}$ in footnote a, except that CTAB is used as PTC in entries 13 and 28, emim ${ }^{+} \mathrm{Cl}^{-}$in entries 14 and 29, whereas in entries 15 and 30, no phase-transfer catalyst was present.

Various factors influence the catalytic effectiveness of phase-transfer catalysts. Accessibility of the positive charge of the quaternary nitrogen cation for complexation with the reacting anion, distribution of the ion pairs or complex in the organic phase, polarizability of the positive charge of the cation (i.e., through resonance in the case of imidazolium), and the polarity of the organic phase are important factors determining the extent of anion transfer from the aqueous phase to the organic phase as well as the separation of the ion pair when the alkoxide is reacting presumably during the rate- determining step. These factors will determine whether a reaction proceeds at an acceptable rate or fails to proceed at all. The solubilities of bis-quaternary compounds decrease in aqueous medium with an increase in alkyl chain length. It is observed that bis-piperidinium compounds 1d and 1e (entry 4 and 5) possessing butyl and hexyl side chains in their structures, showed better results than the rest of the compounds in the series. A similar observation is made for bis-pyrrolidinium compounds where compounds $\mathbf{2 d}$ and $\mathbf{2 e}$ (entry 19 and 20) showed better phase-transfer activity as compared to the rest of compounds in the 
series. This may lead us to understand that optimum phase-transfer activity depends upon the length of the alkyl chain in the phase-transfer catalyst structure and its solubility in the reaction medium. Phase-transfer activity of compounds with a larger alkyl chain is decreased due to their decreased solubility in aqueous medium.

\section{Evaluation as $\mathbf{P T C}$ in $\mathbf{N}$-alkylation reactions}

Recently, a report has been published demonstrating the utilization of quaternary ammonium compounds and pyridinophanes for the synthesis of compounds 4a-4e, (Scheme 4) producing lower yields (up to $35 \%$ for compound 4a) after stirring for quite long times $(16 \mathrm{~h}){ }^{23}$ To test the utility of the presently synthesized bis-piperidinium and bis-pyrrolidinium compounds as phasetransfer catalysts, N-alkylation of these $\mathrm{N}$-heterocycles was performed under standard conditions. In a typical experiment, $\mathrm{N}$-alkylation of imidazole, benzimidazole and benzotriazole was performed with alkyl bromides under phase-transfer catalytic conditions using aq. $\mathrm{NaOH}$ $(25 \%)$ solution and acetonitrile in the presence of bis-piperidinium 1a-1l or bis-pyrrolidinium compounds 2a-2l. In order to compare the phase-transfer catalytic activity of the catalysts 1a-1l and 2a-2l against conventional phase-transfer catalysts, N-alkylation was performed using cetyltrimethylammonium bromide (CTAB) and 1-ethyl-3-methylimidazolium chloride $\left(\mathrm{emim}^{+} \mathrm{Cl}^{-}\right)$phase-transfer catalysts. The prepared alkylated products were characterized and confirmed by spectroscopic methods.

The results for N-alkylation of imidazole, benzimidazole and benzotriazole using bispiperidinium compounds $\mathbf{1 a - 1 1}$ are summarized in Table 2 while those where bis-pyrrolidinium compounds 2a-2l are employed as phase-transfer catalysts are presented in Table 3. As indicated by the results, bis-piperidinium and bis-pyrrolidinium compounds significantly accelerated the rate of reaction as compared to traditional $\mathrm{CTAB}$ and emim ${ }^{+} \mathrm{Cl}^{-}$phase-transfer catalysts. This enhanced activity may be attributed to presence of two cationic centers in the bis-piperidinium and bis-pyrrolidinium compounds.
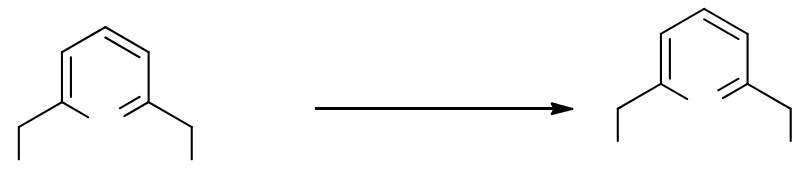

4a: $\mathrm{X}=\mathrm{CH}, \mathrm{Ar}=$ Imidazole

4b: $\mathrm{X}=\mathrm{CH}, \mathrm{Ar}=$ Benzimidazole

4c: $\mathrm{X}=\mathrm{N}, \mathrm{Ar}=$ Imidazole

4d: $X=N, A r=$ Benzimidazole

4e: $X=N, A r=$ Benzotriazole

\section{Scheme 4}


Table 2. Phase-transfer catalyzed N-alkylation of imidazole, benzimidazole and benzotriazole using bis-piperidinium compounds 1a-1l as phase-transfer catalysts

\begin{tabular}{ccccccc}
\hline \multirow{2}{*}{ Entry } & PTC & \multicolumn{5}{c}{ \% Yield $^{\text {a }}$} \\
\cline { 3 - 7 } & & $\mathbf{4 a}$ & $\mathbf{4 b}$ & $\mathbf{4 c}$ & $\mathbf{4 d}$ & $\mathbf{4 e}$ \\
\hline 31 & $\mathbf{1 a}$ & 52 & 54 & 59 & 51 & 44 \\
32 & $\mathbf{1 b}$ & 56 & 61 & 56 & 54 & 48 \\
33 & $\mathbf{1 c}$ & 58 & 67 & 63 & 59 & 46 \\
34 & $\mathbf{1 d}$ & 64 & 74 & 68 & 66 & 55 \\
35 & $\mathbf{1 e}$ & 61 & 72 & 64 & 64 & 57 \\
36 & $\mathbf{1 f}$ & 59 & 66 & 51 & 54 & 56 \\
37 & $\mathbf{1 g}$ & 51 & 58 & 49 & 58 & 61 \\
38 & $\mathbf{1 h}$ & 54 & 51 & 50 & 44 & 51 \\
39 & $\mathbf{1 i}$ & 52 & 32 & 44 & 46 & 43 \\
40 & $\mathbf{1 i}$ & 48 & 38 & 56 & 51 & 46 \\
41 & $\mathbf{1 k}$ & 51 & 45 & 51 & 54 & 39 \\
42 & $\mathbf{1 l}$ & 44 & 46 & 54 & 57 & 45 \\
43 & CTAB & 53 & 52 & 65 & 63 & 49 \\
44 & emim $^{+} \mathrm{Cl}^{-}$ & 29 & 22 & 16 & 26 & 16 \\
45 & None $^{-}$ & 6 & 10 & 4 & 7 & 8 \\
\hline
\end{tabular}

${ }^{\text {a }}$ Isolated yield

Table 3. Phase-transfer catalyzed N-alkylation of imidazole, benzimidazole and benzotriazole using bis-pyrrolidinium compounds $\mathbf{2 a - 2 l}$ as phase-transfer catalysts

\begin{tabular}{ccccccc}
\hline Entry & PTC & \multicolumn{5}{c}{ \% Yield $^{\text {a }}$} \\
\cline { 3 - 7 } & & $\mathbf{4 a}$ & $\mathbf{4 b}$ & $\mathbf{4 c}$ & $\mathbf{4 d}$ & $\mathbf{4 e}$ \\
\hline 46 & $\mathbf{2 a}$ & 39 & 44 & 31 & 41 & 29 \\
47 & $\mathbf{2 b}$ & 42 & 51 & 47 & 41 & 34 \\
48 & $\mathbf{2 c}$ & 52 & 59 & 53 & 51 & 39 \\
49 & $\mathbf{2 d}$ & 60 & 65 & 59 & 60 & 52 \\
50 & $\mathbf{2}$ & 64 & 74 & 63 & 60 & 53 \\
51 & $\mathbf{2 f}$ & 61 & 63 & 58 & 52 & 55 \\
52 & $\mathbf{2 g}$ & 50 & 59 & 53 & 54 & 52 \\
53 & $\mathbf{2 h}$ & 48 & 49 & 44 & 41 & 41 \\
54 & $\mathbf{2 i}$ & 44 & 36 & 48 & 47 & 39 \\
55 & $\mathbf{2 i}$ & 52 & 48 & 51 & 54 & 40 \\
56 & $\mathbf{2 k}$ & 46 & 41 & 54 & 52 & 43 \\
57 & $\mathbf{2 l}$ & 49 & 45 & 48 & 51 & 44 \\
58 & $\mathrm{CTAB}^{-}$ & 53 & 52 & 65 & 63 & 49 \\
59 & emim $^{+} \mathrm{Cl}^{-}$ & 29 & 22 & 16 & 26 & 16 \\
60 & None & 6 & 10 & 4 & 7 & 8 \\
\hline
\end{tabular}

${ }^{\mathrm{a}}$ Isolated yield 


\section{Conclusions}

In conclusion, new series of bis-piperidinium 1a-1l and bis-pyrrolidinium 2a-2l compounds are prepared which are well suited as phase-transfer catalysts for etherification and $\mathrm{N}$-alkylation reactions, as demonstrated for 1-octanol, (benz)imidazole and benzotriazole. The phase-transfer activities of these catalysts were compared with traditionally used cetyltrimethylammonium bromide (CTAB) and 1-ethyl-3-methyl-imidazolium chloride $\left(\mathrm{emim}^{+} \mathrm{Cl}^{-}\right)$phase-transfer catalysts. The results prove that the dicationic bis-piperidinium and bis-pyrrolidinium can act as efficient phase-transfer catalysts. Syntheses of related di-cationic salts, and studies of the effect of counter-anions are underway.

\section{Experimental Section}

General. All chemicals were purchased from Sigma-Adrich. ${ }^{1} \mathrm{H}$ NMR spectra were recorded on a Bruker DPX at $400 \mathrm{MHz} .{ }^{13} \mathrm{C}$ NMR spectra were recorded on Bruker DPX at $100 \mathrm{MHz}$.

\section{General procedure for the preparation of bis-piperidinium / bis-pyrrolidinium compounds} (1a-11, 2a-2l)

Piperidine or pyrrolidine $\left(20 \mathrm{mmol}\right.$ ) was dissolved in $20 \mathrm{~mL}$ of dried THF. $12 \mathrm{mmol}$ of $\mathrm{K}_{2} \mathrm{CO}_{3}$ (4.15 g, $30 \mathrm{mmol})$ was added and the reaction mixture was stirred for 10 minutes. 1,4-Bis (bromomethyl)benzene (2.64 g, $10 \mathrm{mmol}$ ) was added slowly, and stirring was continued until completion of the reaction, as indicated by TLC. Then the THF was (rotary) evaporated. Water $(40 \mathrm{~mL})$ was added and the mixture stirred for a further 10 minutes. The alkylated product was filtered and dried. The obtained product was quaternized with two moles of alkyl halide in acetonitrile to yield the desired catalyst.

1,1'-(1,4-Phenylenebis(methylene))bis(1-methylpiperidinium)di-iodide $\quad$ (1a). 1,4-Bis(piperidin-1-ylmethyl)benzene $(2.724 \mathrm{~g}, 10 \mathrm{mmol})$ was dissolved in $20 \mathrm{~mL}$ THF. Iodomethane $(2.839 \mathrm{~g}, 20 \mathrm{mmol})$ was added and the mixture stirred for 48 hours. THF was evaporated to yield a white powder which was then washed with diethyl ether to obtain the pure product (yield $81 \%$ ). The product was recrystallized from hot water. Found: C, 42.73; H, 5.54; N, 5.83; Calcd: $\mathrm{C}, 43.18 ; \mathrm{H}, 6.16$; N, 5.04. 1H NMR $\left(\mathrm{D}_{2} \mathrm{O}\right), \delta: 7.12(\mathrm{~s}, 4 \mathrm{H}), 4.46(\mathrm{~s}, 4 \mathrm{H}), 3.35-3.20(\mathrm{~m}, 8 \mathrm{H})$, $2.86(\mathrm{~s}, 6 \mathrm{H}), 1.90-1.76(\mathrm{~m}, 8 \mathrm{H}), 1.68-1.43(\mathrm{~m}, 4 \mathrm{H}){ }^{13} \mathrm{C} \delta: 131.1,127.8,66.7,61.1,48.8,21.7$, 20.6 .

1,1'-(1,4-Phenylene-bis(methylene))bis(1-ethylpiperidinium) dibromide (1b). The same procedure was used as for 1a, but with 1-iodoethane as the alkylating agent. Yield $85 \%$. Found: C, 45.09; H, 6.95; N, 4.53; Calcd: C, 45.22; H, 6.55; N, 4.79\% ${ }^{1} \mathrm{H}$ NMR $\left(\mathrm{D}_{2} \mathrm{O}\right), \delta 7.13(\mathrm{~s}, 4 \mathrm{H})$, $4.68(\mathrm{~s}, 4 \mathrm{H}), 3.34(\mathrm{q}, J=7.23,7.32,7.28 \mathrm{~Hz}, 4 \mathrm{H}), 3.28(\mathrm{~m}, 8 \mathrm{H}), 1.54(\mathrm{~m}, 8 \mathrm{H}), 1.35(\mathrm{~m}, 4 \mathrm{H})$, $1.25(\mathrm{t}, J=7.16,7.20,6 \mathrm{H}) .{ }^{13} \mathrm{C} \mathrm{NMR}, \delta 132.2,128.9,66.3,61.3,59.6,27.3,21.9,9.8$. 
1,1'-(1,4-Phenylenebis(methylene))bis(1-allylpiperidinium) dibromide (1c). The same procedure was used as for 1a, but with allyl bromide as the alkylating agent. (Yield 83\%) [Found: C, 46.93; H, 6.87; N, 4.19; Calcd: C, 47.38; H, 6.30; N, 4.60. ${ }^{1} \mathrm{H}$ NMR $\left(\mathrm{D}_{2} \mathrm{O},\right) \delta 7.15(\mathrm{~s}$, $4 \mathrm{H}), 5.81(\mathrm{~m}, 2 \mathrm{H}), 5.29(\mathrm{~m}, 4 \mathrm{H}), 4.66(\mathrm{~s}, 4 \mathrm{H}), 4.02(\mathrm{~d}, 4 \mathrm{H}), 3.22(\mathrm{~m}, 8 \mathrm{H}), 1.62(\mathrm{~m}, 8 \mathrm{H}), 1.28(\mathrm{~m}$, 4H) ${ }^{13}$ C NMR: $\delta 131.7,129.5,124.7,109.6,67.6,63.4,58.2,26.7,20.3$.

1,1'-(1,4-Phenylenebis(methylene))bis(1-butylpiperidinium) dibromide (1d). The same procedure was used as for 1a, but with 1-iodobutane as the alkylating agent. Yield $81 \%$. Found: $\mathrm{C}, 48.21 ; \mathrm{H}, 7.01 ; \mathrm{N}, 4.84$. Calcd: $\mathrm{C}, 48.76 ; \mathrm{H}, 7.24 ; \mathrm{N}, 4.37 .{ }^{1} \mathrm{H}$ NMR $\left(\mathrm{D}_{2} \mathrm{O}\right), \delta 7.17(\mathrm{~s}, 4 \mathrm{H})$, $4.64(\mathrm{~s}, 4 \mathrm{H}), 3.46-3.33(\mathrm{~m}, 12 \mathrm{H}), 2.171 .96(\mathrm{~m}, 12 \mathrm{H}), 1.58-1.33(\mathrm{~m}, 8 \mathrm{H}), 1.06(\mathrm{t}, J=7.12,7.14$ $\mathrm{Hz}, 6 \mathrm{H}) .{ }^{13} \mathrm{C}$ NMR: $\delta$ 132.9, 131.1, 67.8, 59.6, 52.9, 27.8, 22.7, 20.1, 16.8, 11.7 .

1,1'-(1,4-Phenylenebis(methylene))bis(1-hexylpiperidinium) dibromide (1e). The same procedure was used as for 1a, but with 1-bromohexane as the alkylating agent. Yield $79 \%$. Found: C, 59.11; H, 8.76; N, 4.97. Calcd: C, 59.80; H, 9.03; N, 4.65\%. ${ }^{1} \mathrm{H}$ NMR $\left(\mathrm{D}_{2} \mathrm{O}\right), \delta 7.31$ $(\mathrm{s}, 4 \mathrm{H}), 4.69(\mathrm{~s}, 4 \mathrm{H}), 3.54-3.40(\mathrm{~m}, 12 \mathrm{H}), 2.16-2.01(\mathrm{~m}, 12 \mathrm{H}), 1.68-1.46(\mathrm{~m}, 16 \mathrm{H}), 1.12(\mathrm{t}, J=$ 7.46, 7.36 Hz, 6H). ${ }^{13} \mathrm{C}$ NMR: $\delta 131.4,129.8,66.9,62.4,57.8,34.7,28.6,27.5,25.3,23.1,21.4$, 13.2 .

1,1'-(1,4-Phenylenebis(methylene))bis(1-octylpiperidinium) dibromide (1f). The same procedure was used, but with 1-bromohexane as the alkylating agent. Yield 74\%. Found: C, 62.28; H, 9.07; N, 4.02. Calcd: C, 62.00; H, 9.49; N, 4.25. ${ }^{1} \mathrm{H}$ NMR $\left(\mathrm{D}_{2} \mathrm{O}\right), \delta 7.34(\mathrm{~s}, 4 \mathrm{H}), 4.68$ (s, 4H), 3.48-3.34 (m, 12H), 2.14-1.97 (m, 12H), 1.57-1.33 (m, 24H), 1.02 (t, J = 7.22, $7.14 \mathrm{~Hz}$, 6H). ${ }^{13} \mathrm{C}$ NMR: $\delta 131.3,130.1,66.6,62.8,57.3,32.2,30.7,29.3,26.4,23.8,22.9,21.6,14.8$.

1,1'-(1,4-Phenylenebis(methylene))bis(1-dodecylpiperidinium) dibromide (1g). The same procedure was used, but with 1-bromododecane as the alkylating agent. Yield $78 \%$. Found: $\mathrm{C}$, 65.97; H, 9.37; N, 3.29. Calcd: C, 65.44; H, 10.20; N, 3.63. ${ }^{1} \mathrm{H}$ NMR $\left(\mathrm{D}_{2} \mathrm{O}\right), \delta 7.31$ (s, 4H), 4.62 (s, 4H), 3.55-3.38 (m, 12H), 2.12-1.98 (m, 12H), 1.58-1.38 (m, 16H), 1.30-1.14 (m, 24H), 1.08 $(\mathrm{t}, J=7.19,7.16,6 \mathrm{H}) .{ }^{13} \mathrm{C}$ NMR: $\delta$ 131.6, 130.2, 67.3, 62.1, 56.8, 33.7, 31.6, 30.7, 29.5, 26.9, 24.2, 22.9, 21.4, 14.4.

1,1'-(1,4-Phenylenebis(methylene))bis(1-hexadecylpiperidinium) dibromide (1h). The same procedure was used as for 1a, but with 1-bromohexadecane as alkylating agent. Yield $43 \%$. Found: C, 68.41; H, 10.73; N, 3.17. Calcd; C, 68.00; H, 10.73; N, 3.17. ${ }^{1} \mathrm{H}$ NMR $\left(\mathrm{D}_{2} \mathrm{O}\right), \delta 7.29$ (s, $4 \mathrm{H}), 4.66(\mathrm{~s}, 4 \mathrm{H}), 3.62-3.49(\mathrm{~m}, 12 \mathrm{H}), 2.11-1.96(\mathrm{~m}, 12 \mathrm{H}), 1.54-1.37(\mathrm{~m}, 16 \mathrm{H}), 1.26-1.10(\mathrm{~m}$, $40 \mathrm{H}), 1.04(\mathrm{t}, J=7.14,7.12,6 \mathrm{H}) .{ }^{13} \mathrm{C}$ NMR: $\delta 131.4,130.1,67.5,62.4,56.4,33.9,32.1,31.5$, 29.7, 26.7, 23.8, 21.9, 21.2, 14.8.

1,1'-(1,4-Phenylenebis(methylene))bis(1-octadecylpiperidinium) dibromide (1i). 1Bromooctadecane was used as the alkylating agent. Yield 33\%. Found: C, 69.51; H, 11.13; N, 2.41. Calcd C, 69.06; H, 10.95; N, 2.98. ${ }^{1} \mathrm{H}$ NMR $\left(\mathrm{D}_{2} \mathrm{O}\right), \delta: 7.28$ (s, 4H), $4.67(\mathrm{~s}, 4 \mathrm{H}), 3.60-3.46$ (m, 12H), 2.09-1.91 (m, 12H), 1.52-1.33 (m, 16H), 1.24-1.10 (m, 48H), $1.02(\mathrm{t}, J=7.12,7.16$, $6 \mathrm{H}) .{ }^{13} \mathrm{C}$ NMR: $\delta 131.6,130.2,66.9,61.8,57.2,34.2,31.9,30.4,29.5,26.3,23.6,21.7,21.3$, 14.9 . 
1,1'-(1,4-Phenylenebis(methylene))bis(1-benzylpiperidinium) dibromide (1j). Benzyl bromide was used as the alkylating agent. Yield of product $84 \%$. Found: C, 62.09; H, 6.19; N, 4.11; Calcd: C, 62.55; H, 6.89; N, 4.56. ${ }^{1} \mathrm{H}$ NMR $\left(\mathrm{D}_{2} \mathrm{O}\right), \delta: 7.54-7.26(\mathrm{~m}, 10 \mathrm{H}), 7.23$ (s, 4H), $4.64(\mathrm{~s}, 8 \mathrm{H}), 3.54-3.40(\mathrm{~m}, 8 \mathrm{H}), 2.05-1.93(\mathrm{~m}, 8 \mathrm{H}), 1.59-1.38(\mathrm{~m}, 4 \mathrm{H}) .{ }^{13} \mathrm{C} \mathrm{NMR}, \delta: 132.6$, $131.5,131.3,130.3,129.6,125.9,67.5,59.5,32.7,20.6$.

1,1'-(1,4-Phenylenebis(methylene))bis(1-(4-bromobenzyl)piperidinium) dibromide (1k). 4Bromobenzyl bromide was used as the alkylating agent. Yield of product $80 \%$. Found: C, 50.08; H, 5.64; N, 3.92; Calcd: C, 49.77; H, 5.22; N, 3.63. ${ }^{1} \mathrm{H}$ NMR $\left(\mathrm{D}_{2} \mathrm{O}\right), \delta: 7.56(\mathrm{~d}, J=8.85 \mathrm{~Hz}, 4 \mathrm{H})$, $7.36(\mathrm{~d}, J=7.78 \mathrm{~Hz}, 4 \mathrm{H}), 7.23(\mathrm{~s}, 4 \mathrm{H}), 4.63(\mathrm{~s}, 8 \mathrm{H}), 3.44-3.26(\mathrm{~m}, 8 \mathrm{H}), 2.11-1.95(\mathrm{~m}, 8 \mathrm{H}), 1.56-$ $1.31(\mathrm{~m}, 4 \mathrm{H}) .{ }^{13} \mathrm{C}$ NMR, $\delta: 131.9,131.7,131.4,131.2,130.7,118.4,67.3,58.9,31.9,20.7$.

1,1'-(1,4-Phenylenebis(methylene))bis(1-(3-bromobenzyl)piperidinium)-dibromide (11). 3Bromobenzyl bromide was used as the alkylating agent. Yield of product $81 \%$. Found: $\mathrm{C}, 50.11$; H, 5.48; N, 3.41; Calcd: C, 49.77; H, 5.22; N, 3.63. ${ }^{1} \mathrm{H}$ NMR $\left(\mathrm{D}_{2} \mathrm{O}\right), \delta: 7.46-7.38(\mathrm{~m}, 4 \mathrm{H}), 7.35-$ $7.28(\mathrm{~m}, 4 \mathrm{H}), 7.25(\mathrm{~s}, 4 \mathrm{H}), 4.65(\mathrm{~s}, 8 \mathrm{H}), 3.38-3.20(\mathrm{~m}, 8 \mathrm{H}), 2.16-1.98(\mathrm{~m}, 8 \mathrm{H}), 1.60-1.42(\mathrm{~m}$, $4 \mathrm{H}) .{ }^{13} \mathrm{C}$ NMR, $\delta: 135.3,134.8,133.1,131.5,130.2,129.2,127.5,122.4,67.4,61.7,58.5,32.3$, 20.8 .

1,1'-(1,4-Phenylenebis(methylene))bis(1-methylpyrrolidinium)di-iodide (2a). 1,4-Bis(pyrrolidin-1-ylmethyl)benzene $(10 \mathrm{mmol}, 2.444 \mathrm{~g}, 10 \mathrm{mmol})$ was dissolved in $20 \mathrm{~mL}$ acetonitrile. 1-iodomethane $(2.839 \mathrm{~g}, 20 \mathrm{mmol})$ was added and the mixture was stirred for 48 hours. The acetonitrile was evaporated off, to yield the white powder product which was recrystallized from hot water. Yield 80\%. Found: C, 41.28; H, 5.19; N, 5.51; Calcd: C, 40.93; H, 5.42; N, 5.30. ${ }^{1} \mathrm{H}$ NMR $\left(\mathrm{D}_{2} \mathrm{O}\right), \delta: 7.21(\mathrm{~s}, 4 \mathrm{H}), 4.63(\mathrm{~s}, 4 \mathrm{H}), 3.58(\mathrm{~s}, 6 \mathrm{H}), 3.53-3.35(\mathrm{~m}, 8 \mathrm{H})$, 2.02-1.83 (m, 8H). ${ }^{13} \mathrm{C}$ NMR. $\delta: 131.8,129.9,72.6,67.4,53.8,24.8$.

1,1'-(1,4-Phenylenebis(methylene))bis(1-ethylpyrrolidinium)di-iodide (2b). Quaternization with 1-iodoethane afforded the desired product. Yield 71\%. Found: C, 43.82; H, 6.68; N, 5.24. Calcd: C, 43.68; H, 6.76; N, 5.04]. ${ }^{1} \mathrm{H}$ NMR $\left(\mathrm{D}_{2} \mathrm{O}\right), \delta: 7.24(\mathrm{~s}, 4 \mathrm{H}), 4.64(\mathrm{~s}, 4 \mathrm{H}), 3.68-3.28$ (m, 12H), 2.04-1.77 (m, 8H), $1.79(\mathrm{t}, J=7.21,7.16 \mathrm{~Hz}, 6 \mathrm{H}) .{ }^{13} \mathrm{C} \mathrm{NMR}, \delta: 132.3,129.2,71.3,66.3$, 57.4, 24.2, 7.1.

1,1'-(1,4-Phenylenebis(methylene))bis(1-allylpyrrolidinium) dibromide (2c). The same procedure was used as for $\mathbf{2 b}$, but with allyl iodide as the alkylating agent. Yield $74 \%$. Found: $\mathrm{C}$, 54.11; H, 7.38; N, 5.91. Calcd: C, 54.33; H, 7.05; N, 5.76. ${ }^{1} \mathrm{H}$ NMR $\left(\mathrm{D}_{2} \mathrm{O}\right), \delta$ : 7.22 (s, $\left.4 \mathrm{H}\right)$, 5.85$5.65(\mathrm{~m}, 2 \mathrm{H}), 5.22-4.94(\mathrm{~m}, 4 \mathrm{H}), 4.61(\mathrm{~s}, 4 \mathrm{H}), 4.07(\mathrm{~d}, J=7.64 \mathrm{~Hz}, 4 \mathrm{H}), 3.48-3.25(\mathrm{~m}, 8 \mathrm{H})$, 2.06-1.84 (m, 8H). ${ }^{13} \mathrm{C}$ NMR, $\delta: 131.5,129.6,128.1,115.2,71.8,66.8,63.9,23.8$.

1,1'-(1,4-Phenylenebis(methylene))bis(1-butylpyrrolidinium)di-iodide $\quad$ (2d). The same procedure was used as for $\mathbf{2 b}$, but with 1-iodobutane as the alkylating agent. Yield $67 \%$. Found: C, 47.34; H, 6.69; N, 4.36. Calcd: C, 47.07; H, 6.91; N, 4.57. ${ }^{1} \mathrm{H}$ NMR $\left(\mathrm{D}_{2} \mathrm{O}\right), \delta: 7.21(\mathrm{~s}, 4 \mathrm{H})$, $4.62(\mathrm{~s}, 4 \mathrm{H}), 3.52-3.32(\mathrm{~m}, 12 \mathrm{H}), 2.01-1.73(\mathrm{~m}, 12 \mathrm{H}), 1.59-1.36(\mathrm{~m}, 4 \mathrm{H}), 1.13(\mathrm{t}, J=7.16,7.14$ $\mathrm{Hz}, 6 \mathrm{H}) .{ }^{13} \mathrm{C} \mathrm{NMR}, \delta: 131.8,129.9,72.3,66.1,63.2,25.2,24.1,20.8,14.4$.

1,1'-(1,4-Phenylenebis(methylene))bis(1-hexylpyrrolidinium) dibromide (2e). The same procedure was used as for 2B, but with 1-bromohexane as alkylating agent. Yield $61 \%$. Found: 
C, 58.21; H, 8.58; N, 5.04; Calcd: C, 58.54; H, 8.77; N, 4.88. ${ }^{1} \mathrm{H}$ NMR $\left(\mathrm{D}_{2} \mathrm{O}\right), \delta: 7.25(\mathrm{~s}, 4 \mathrm{H})$, $4.62(\mathrm{~s}, 4 \mathrm{H}), 3.64-3.42(\mathrm{~m}, 12 \mathrm{H}), 2.06-1.81(\mathrm{~m}, 12 \mathrm{H}), 1.41-1.23(\mathrm{~m}, 12 \mathrm{H}), 1.15(\mathrm{t}, \mathrm{J}=7.21,7.17$ $\mathrm{Hz}, 6 \mathrm{H}) .{ }^{13} \mathrm{C} \mathrm{NMR}, \delta: 131.6,129.7,72.9,67.1,62.4,33.7,28.9,24.7,24.1,22.8,14.8$.

1,1'-(1,4-Phenylenebis(methylene))bis(1-octylpyrrolidinium) dibromide (2f). 1-Bromooctane was used as the alkylating agent. Yield 63\%. Found: C, 61.13; H, 9.48; N, 4.59; Calcd: C, 60.95; H, 9.27; N, 4.44. ${ }^{1} \mathrm{H}$ NMR $\left(\mathrm{D}_{2} \mathrm{O}\right) \delta 7.21(\mathrm{~s}, 4 \mathrm{H}), 4.65(\mathrm{~s}, 4 \mathrm{H}), 3.58-3.27(\mathrm{~m}, 12 \mathrm{H}), 2.05-$ $1.78(\mathrm{~m}, 12 \mathrm{H}), 1.47-1.16(\mathrm{~m}, 20 \mathrm{H}), 1.04(\mathrm{t}, J=7.19,7.16 \mathrm{~Hz}, 6 \mathrm{H}) .{ }^{13} \mathrm{C} \mathrm{NMR}, \delta: 131.2,129.4$, $72.3,66.6,61.7,33.3,30.7,28.6,24.1,23.7,21.2,15.2$.

1,1'-(1,4-Phenylenebis(methylene))bis(1-dodecylpyrrolidinium) dibromide (2g). 1-Bromododecane was used as the alkylating agent. Yield 56\%. Found: C, 64.52; H, 9.88; N, 3.91. Calcd: $\mathrm{C}, 64.67 ; \mathrm{H}, 10.04 ; \mathrm{N}, 3.77 .{ }^{1} \mathrm{H} \operatorname{NMR}\left(\mathrm{D}_{2} \mathrm{O}\right), \delta: 7.25(\mathrm{~s}, 4 \mathrm{H}), 4.68(\mathrm{~s}, 4 \mathrm{H}), 3.56-3.31(\mathrm{~m}, 12 \mathrm{H})$, 2.09-1.84 (m, 12H), 1.44-1.12 (m, 36H), $1.06(\mathrm{t}, J=7.14,7.11 \mathrm{~Hz}, 6 \mathrm{H}) .{ }^{13} \mathrm{C} \mathrm{NMR}, \delta: 130.9$, $129.1,72.1,66.8,61.3,32.8,30.9,30.1,29.3,23.8,23.6,21.6,14.7$.

1,1'-(1,4-Phenylenebis(methylene))bis(1-hexadecylpyrrolidinium) dibromide (2h). 1Bromohexadecane was used as the alkylating agent. Yield 48\%. Found: C, 67.30; H, 10.83; N, 3.12. Calcd: C, 67.42; H, 10.61; N, 3.28. ${ }^{1} \mathrm{H}$ NMR ( $\left.\mathrm{D}_{2} \mathrm{O}\right), \delta: 7.26$ (s, $\left.4 \mathrm{H}\right), 4.62(\mathrm{~s}, 4 \mathrm{H}), 3.54-3.28$ $(\mathrm{m}, 12 \mathrm{H}), 2.09-1.81(\mathrm{~m}, 12 \mathrm{H}), 1.42-1.11(\mathrm{~m}, 52 \mathrm{H}), 1.03(\mathrm{t}, J=7.13,7.08 \mathrm{~Hz}, 6 \mathrm{H}) .{ }^{13} \mathrm{C}$ NMR, $\delta$ : $131.7,129.7,72.8,66.1,62.3,33.5,30.3,29.8,28.7,24.2,23.5,21.4,15.2$.

1,1'-(1,4-Phenylenebis(methylene))bis(1-octadecylpyrrolidinium) dibromide (2i). 1-Bromohexadecane was used as the alkylating agent. Yield 56\%. Found: C, 68.71; H, 10.57; N, 3.22. Calcd: C, 68.55; H, 10.84; N, 3.07. ${ }^{1} \mathrm{H}$ NMR (DMSO-d 6 ) $\delta: 7.29$ (s, $\left.4 \mathrm{H}\right), 4.68(\mathrm{~s}, 4 \mathrm{H}), 3.56-3.21$ $(\mathrm{m}, 12 \mathrm{H}), 2.03-1.75(\mathrm{~m}, 12 \mathrm{H}), 1.47-1.16(\mathrm{~m}, 60 \mathrm{H}), 1.08(\mathrm{t}, J=7.16,7.11 \mathrm{~Hz}, 6 \mathrm{H}) .{ }^{13} \mathrm{C} \mathrm{NMR}, \delta$ : $131.3,129.2,71.7,65.8,61.2,33.7,30.7,30.1,29.3,24.7,24.3,21.9,15.6$.

1,1'-(1,4-Phenylenebis(methylene))bis(1-benzylpyrrolidinium) dibromide (2j). Benzyl bromide was used as the alkylating agent. Yield 85\%. Found: C, 61.27; H, 6.81; N, 4.58. Calcd: C, 61.44; H, 6.53; N, 4.78. ${ }^{1} \mathrm{H}$ NMR (DMSO-d $) \delta$ 7.46-7.19 (m, $\left.14 \mathrm{H}\right), 4.63(\mathrm{~s}, 8 \mathrm{H}), 3.51-3.18$ $(\mathrm{m}, 8 \mathrm{H}), 2.02-1.76(\mathrm{~m}, 8 \mathrm{H}) .{ }^{13} \mathrm{C} \mathrm{NMR}, \delta: 133.3,131.9,129.6,129.2,128.8,126.3,71.6,64.8$, 23.8 .

1,1'-(1,4-Phenylenebis(methylene))bis(1-(4-bromobenzyl)pyrrolidinium) dibromide (2k). 4Bromobenzyl bromide was used as the alkylating agent. Yield 80\%. Found: C, 48.21; H, 4.51; N, 3.61. Calcd: C, 48.41; H, 4.88; N, 3.76. ${ }^{1} \mathrm{H}$ NMR (DMSO-d $) \delta 7.63$ (d, J=8.48, $4 \mathrm{H}$ ), 7.24-7.04 $(\mathrm{m}, 8 \mathrm{H}), 4.68(\mathrm{~s}, 8 \mathrm{H}), 3.55-3.32(\mathrm{~m}, 8 \mathrm{H}), 2.08-1.81(\mathrm{~m}, 8 \mathrm{H}) .{ }^{13} \mathrm{C} \mathrm{NMR}, \delta: 132.8,131.9,131.4$, $131.1,129.6,116.8,71.5,65.8,23.8$.

1,1'-(1,4-Phenylenebis(methylene))bis(1-(3-bromobenzyl)pyrrolidinium) dibromide (2l). 3Bromobenzyl bromide was used as the alkylating agent. Yield 79\%. Found: C, 48.65; H, 4.56; N, 3.58. Calcd: C, 48.41; H, 4.88; N, 3.76. ${ }^{1} \mathrm{H}$ NMR (DMSO- $\left.d_{6}\right) \delta$ 7.66-7.39 (m, 4H), 7.22-7.05 (m, $8 \mathrm{H}), 4.69(\mathrm{~s}, 8 \mathrm{H}), 3.59-3.33(\mathrm{~m}, 8 \mathrm{H}), 2.10-1.78(\mathrm{~m}, 8 \mathrm{H}) .{ }^{13} \mathrm{C} \mathrm{NMR}, \delta: 137.3,134.9,132.8,131.6$, 129.9, 129.1, 128.2, 123.5, 71.7, 66.8, 65.3, 24.7. 


\section{General procedure for etherification reaction under phase-transfer catalysis conditions}

The alkyl halide $(20 \mathrm{mmol})$ was stirred under $\mathrm{N}_{2}$ at $90{ }^{\circ} \mathrm{C}$ with 1-octanol $(1.302 \mathrm{~g}, 10 \mathrm{mmol})$ in aqueous $\mathrm{NaOH}(50 \%, 5 \mathrm{ml})$. The catalyst $(0.8 \mathrm{mmol})$ was added to the reaction mixture and stirring was continued. The reaction mixture was analyzed by HPLC after 60 minutes and the relative quantities of the products and reactants were calculated. The reaction was allowed to complete, as indicated by HPLC, by total or almost complete disappearance of the reactants. The products were characterized by spectroscopic and analytical methods and the results were found in agreement with the literature.

\section{General procedure for $\mathrm{N}$-alkylation of imidazole, benzimidazole and benzotriazole under PTC conditions}

In the presence of phase-transfer catalyst $(0.5 \mathrm{mmol})$, the imidazole, benzimidazole, or benzotriazole $(10 \mathrm{mmol})$ was stirred in $25 \%$ aq. $\mathrm{NaOH}$ and acetonitrile $(12 \mathrm{ml}, 1: 1)$. After 5 minutes, the alkyl dihalide $(5 \mathrm{mmol})$ was added slowly, maintaining the temperature at 25 $35{ }^{\circ} \mathrm{C}$. The reaction was allowed to complete, as indicated by TLC, after which $30 \mathrm{ml}$ water was added and the contents were further stirred for 5 minutes. The reaction mixture was extracted with chloroform $\left(6 \times 25 \mathrm{ml}\right.$ ), the combined extracts dried over $\mathrm{MgSO}_{4}$, and solvent was evaporated to give the $\mathrm{N}$-alkylated product. Spectroscopic and mass analyses confirmed the identity of the products.

\section{Acknowledgements}

The authors are thankful to Higher Education Commission Pakistan for providing financial assistance to complete this project.

\section{References}

1. Jones, R. A. Quaternary Ammonium Salts: Their Use in Phase-Transfer Catalysed Reactions; Academic Press, 2001.

2. Nouguier, R. M.; McHich, M. J. Org. Chem. 1985, 50, 3296.

3. Degani, I.; Dolci, M.; Fochi, R. Synth. Commun. 1980, 10, 161.

4. Jayachandran, J. P.; Wang, M.-L. Synth. Commun. 2001, 31, 2743.

5. Castanet, A. S.; Colobert, F.; Desmurs, J. R.; Schlama, T. J. Mol. Catal. A: Chem. 2002, 182183, 481.

6. Galamb, V.; Alper, H. Transition Met. Chem. 1983, 8, 271.

7. Seol, Y.; Schwartz, F. W. J. Contam. Hydrol. 2000, 44, 185.

8. Ragaini, F. Organometallics 1996, 15, 3572. 
9. Martíanez, G.; Mijangos, C.; Terroba, P.; Millán, J. J. Polym. Sci., Part A: Polym Chem. 1988, 26, 1629.

10. Qiu, L.-G.; Xie, A.-J.; Shen, Y.-H. Colloid Polym. Sci. 2005, 283, 1343.

11. Ali, H. E.-S. Catal. Commun. 2007, 8, 855.

12. Borde, C.; Nardello, V.; Wattebled, L.; Laschewsky, A.; Aubry, J.-M. J. Phys. Org. Chem. 2008, 21, 652.

13. Drumheller, J. E.; Seifert, P. L.; Zaspel, C. E.; Snively, L. O.; Emerson, K. J. Chem. Phys. 1980, 73, 5830.

14. Mlynarčík, D.; Lacko, I.; Devínsky, F. Cell. Mol Life Sci. 1979, 35, 1044.

15. Ohkura, K.; Sukeno, A.; Nagamune, H.; Kourai, H. Bioorg. Med. Chem. 2005, 13, 2579.

16. Patyal, B. R.; Scott, B. L.; Willett, R. D. Phys. Rev. B. 1990, 41, 1657.

17. Tsuneo, T.; Toshihiro, N.; Yasukazu, O. J. Japan Oil Chemists' Soc. 1999, 48, 1397.

18. Wang, M.-L.; Lee, Z.-F.; Wang, F.-S. J. Mol. Catal. A: Chem. 2005, 229, 259.

19. Xianying Shi, J. W. Appl. Organomet. Chem. 2007, 21, 172.

20. Zaspel, C. E.; Snively, L. O.; Emerson, K.; Drumheller, J. E. Bull. Amer. Phys. Soc. 1980, $25,306$.

21. Murguía, M. C.; Vaillard, V. A.; Sánchez, V. G.; Conza, J. D.; Grau, R. J. J. Oleo Sci. 2008, 57, 301 .

22. Freedman, H. H.; Dubois, R. A. Tetrahedron Lett. 1975, 16, 3251.

23. Rajakumar, P.; Dhanasekaran, M. Synthesis 2006, 4, 654. 